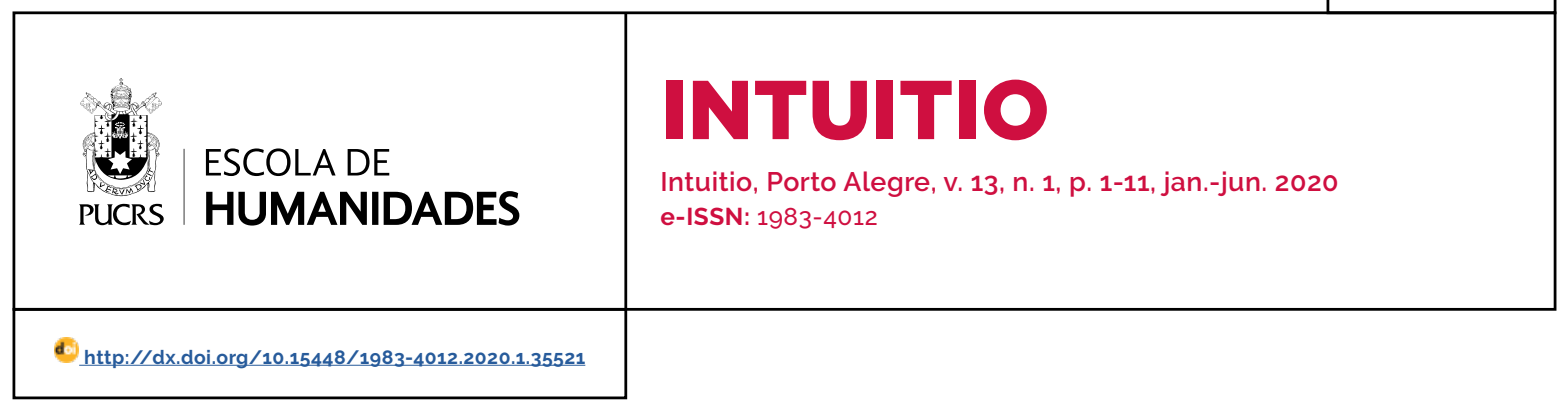

SEÇÃO: ARTIGO

\title{
Epistemologia feminista enquanto uma ramificação da epistemologia social: uma análise a partir de Donna Haraway e Sandra Harding
}

\author{
Feminist epistemology as a branch of social epistemology: an analysis from Donna \\ Haraway and Sandra Harding
}

\section{Camila Palhares}

\section{Barbosa $^{1}$}

orcid.org/0000-0003-2254-5266 camilabarbosa.ri@gmail.com

Recebido em: 3 set. 2019. Aprovado em: 29 jan. 2020 Publicado em: 27 jul. 2020

\section{(c) (1)}

Artigo está licenciado sob forma de uma licença Creative Commons Atribuição 4.0 Internacional.
Resumo: Este trabalho tem como objetivo apresentar uma perspectiva feminista da epistemologia social. A partir dessa, criticar a ideia de universalização da verdade feita através do método tradicional da epistemologia analítica e das ciências, frequentemente ditas como neutras ou não corporificadas. Proponho demonstrar que o pesquisador é um corpo enquanto localização, isto é, está situado socialmente e historicamente, evidenciando suas consequências dentro da pesquisa científica. Para tanto, terei como principal escopo argumentativo as contribuições de Donna Haraway e Sandra Harding a fim de articular a ideia de uma objetividade do conhecimento através de saberes que são localizados. Por fim, apontar essa perspectiva enquanto uma das ramificações essenciais para a epistemologia social.

Palavras-chave: Conhecimento. Epistemologia. Feminismo. Método.

Abstract: This article aims to present a feminist perspective of the social epistemology. From this analysis, criticize the universalization of the truth done through the traditional method of analytic epistemology and sciences, frequently said to be neutral or bodiless. I propose to demonstrate that the researcher is a body as a localization, or, is social and historical situated. To do so, my main argumentative scope will be the contributions of Donna Haraway and Sandra Harding in order to articulate the idea of an objective knowledge through knowledges that are located. Finally, highlight this perspective as an essential ramification to the social epistemology field.

Keywords: Epistemology. Feminism. Knowledge. Method.

\section{Introdução}

Uma leitura feminista da epistemologia e da ciência encontra um incômodo imediato ao apropriar-se destes campos nos quais, tradicionalmente, foram negados a presença feminina: o da objetividade universal do conhecimento a partir de marcadores neutros, isto é, do pesquisador não passional. O primeiro ponto em questão é, certamente, de quem ocupa estes locais de produção de conhecimento: os laboratórios, as salas de aula, as bolsas científicas, costumam ser ocupadas majoritariamente por um mesmo gênero, raça e classe. E, ao mesmo tempo, promovem sua pesquisa enquanto um método neutro e "descorporificado". Esse incômodo com o método surge, como bem 
apontado por Donna Haraway, por quem não ocupa esses lugares, aqueles "a quem não se permite não ter um corpo".2

Neutralidade é uma possibilidade dentro de um discurso privilegiado, ou seja, um discurso que permite o apagamento da dimensão do corpo e da experiência, uma vez que é tomado do ponto de vista universal, comumente associado aos homens brancos que ocupam esses espaços públicos. Essa é a critica mais imediata ao método das ciências e da epistemologia; mas ela não pode ser simplista, na medida em que pode ao mesmo tempo nos afastar, mais uma vez, desse lugar de conhecimento que desde sempre nos foi negado. ${ }^{3}$ Ao apresentar as perspectivas de Donna Haraway e Sandra Harding neste ensaio, busco ir além dessa crítica, apropriando o método e incorporando uma noção de objetividade que possa ampliar a noção de conhecimento e verdade, mas que não se perca completamente em uma leitura relativista que, em muitos sentidos, desfavorecem a própria argumentação feminista nesses campos.

A epistemologia social parece ser um bom ponto de partida para discutir tais noções, na medida em que se caracteriza pela incorporação da interação de indivíduos com o próprio ambiente e com outros indivíduos, e como essa dinâmica se reflete no conhecimento. Segundo Goldman, ${ }^{4}$ a epistemologia social poderia ser dividida em três grandes perspectivas: (1) a do revisionismo, que rejeitaria a noção de verdade como algo externo a ser descoberto no mundo, mas que focaria principalmente em como as relações sociais constroem o mundo como algo simbólico e significante (o construtivismo social e o pós-modernismo inclusos aqui); (2) a do preservacionismo que em grande medida leva a epistemologia tradicional como padrão, mantendo uma leitura individualista do conhecimento, mas utilizando o aspecto social na tomada de decisão através da análise de evidências sociais; e, por fim, (3) a do expansionismo, que ainda mantém premissas da epistemologia tradicional, embora busca expandir, com a epistemologia social, propriedades coletivas e a influência de sistemas sociais alternativos nos resultados epistêmicos.

Quero, entretanto, articular a epistemologia feminista como um quarto viés nesse campo, uma vez que perpassa por todas essas questões e que, ao mesmo tempo, não se enquadram exatamente nas categorias descritas por Goldman. Haraway, por exemplo, vai apresentar duas principais perspectivas adotadas pela epistemologia feminista: por um lado, o argumento da "construção social de todas as formas de conhecimento", 5 onde as fronteiras internas-externas do conhecimento eram demarcadas como "movimentos de poder"; por outro, a utilização de um "empiricismo feminista"6 que através da ciência continua a insistir nos significados legitimos da objetividade, mas que busca um projeto de ciência mais adequado e rico na realidade corporificada da epistemologia.

Enquanto a primeira perspectiva traz as noções de poder e subjetividade para a discussão acerca do conhecimento, de forma que a história coletiva carrega "versões corporificadas da verdade", como resposta às construções hostis da verdade universal masculina abstrata ${ }^{7}$ da epistemologia tradicional, a segunda já quer evitar que, como feministas, "não aprendemos nada sobre física pós-Newton", 8 e busca incorporar uma visão objetiva na doutrina que nos ofereçam vieses comprometidos com explicações adequadas e plausiveis do mundo "real".

\footnotetext{
2 HARAWAY, Donna. Saberes localizados: a questão da ciência para o feminismo e o privilégio da perspectiva parcial. Cadernos Pagu, n. 5, p. 7-41, Campinas, SP: 1995. p. 7.

3 FRASER, Nancy. Rethinking the Public Sphere: contribution to the critique of actually existing democracy. Social Text, n. 25/26, p. 5680, Duke University, 1990; JAGGAR, Alison. Love and knowledge: Emotion in feminist epistemology. Inquiry: An Interdisciplinary Journal of Philosophy, London, v. 32, n. 2, p. 151-176, 1989.

4 GOLDMAN, Alvin. Why Social Epistemology Is Real Epistemology. In: HADDOCK, A.; MILLAR, A.; PRITCHARD, D. (ed). Social Epistemology. New York, US: OUP, 2010. p. 1-28.

5 HARAWAY, Donna. Saberes localizados: a questão da ciência para o feminismo e o privilégio da perspectiva parcial. Cadernos Pagu. Campinas, n. 5. p. 7-41, 1995. p. 9.

6 HARAWAY, Donna. Saberes localizados: a questão da ciência para o feminismo e o privilégio da perspectiva parcial. Cadernos Pagu, Campinas, n. 5, p. 7-41, 1995. p. 15

7 HARDING, S. The Science Question in Feminism. Ithaca, US: Cornell University, 1986. p. 148.

8 HARAWAY, Donna. Saberes localizados: a questão da ciência para o feminismo e o privilégio da perspectiva parcial. Cadernos Pagu. Campinas, n. 5, p.7-41, 1995. p. 9.
} 
Essa dicotomia da epistemologia feminista será o primeiro aspecto analisado neste texto, na medida em que entender as perdas e ganhos para argumentação feminista de cada uma delas é central nessa discussão. Além disso, a partir do aprofundamento da análise dicotômica entre construtivismo social radical e empirismo feminista, proponho uma análise da noção de Haraway acerca dos "saberes localizados" como uma via de diálogo entre essas posições, isto é, ao mesmo tempo que adota uma perspectiva sobre a objetividade, livrando-se do caráter ficcional da leitura feminista, ainda apresenta uma visão corporificada e histórica do social significante. Esse será o segundo ponto a ser destrinchado no decorrer desse texto.

Por fim, proponho com o texto, trazer a contribuição feminista para área da epistemologia e, especialmente, apontá-la como uma das vertentes válidas da epistemologia social. $O$ cerne do argumento é, então, a concepção mais apropriada do conhecimento e objetividade para nossa realidade social, que não permite neutralidade para alguns sujeitos na medida em que não podemos "nos livrar do corpo", mas que ao mesmo tempo consegue contribuir para uma leitura menos "masculina abstrata" do que consideramos na atual metanarrativa sobre objetividade.

\section{A dicotomia da epistemologia feminista}

Em Why Social Epistemology Is Real Epistemology, Goldman ${ }^{9}$ argumenta que a epistemologia analítica tradicional tem como caracteristicas principais: a) agentes epistêmicos individuais; b) avaliação epistêmica ou normativa por conceitos como justificativa, racionalidade e conhecimento; c) assume padrões normativos de racionalidade e justificação com validade objetiva; d) as noções epistêmicas como conhecimento e justificação levam à verdade; e) verdades são objetivas e independentes da mente..$^{10}$ Assim, uma mudança substancial da epistemologia analítica para a social é a noção de agentes epistêmicos coletivos, isto é, os sistemas de crenças, justificações e racionalidade surgem das dinâmicas de interações do indivíduo com o social. Nesse sentido, podemos aproximar a epistemologia feminista como uma ramificação da social, uma vez que trabalhar com a ideia de um corpo socialmente significado e sua representação da objetividade depende de uma visão coletiva, do indivíduo com o todo social.

Apesar de podermos aproximar a epistemologia feminista da social, como descrita por Goldman, quero diferenciá-la das categorias apresentas acima a partir da critica aos sistemas dualistas desenvolvidos por Haraway ${ }^{11}$ que contrapõem biológico e social, corpo e mente, objetividade e subjetividade, animal e humano, racionalidade e emoção, verdade e mentira, homem e mulher etc. ${ }^{12}$. A perspectiva feminista oferece diferentes abordagens epistemológicas para articular a questão do conhecimento. Segundo Sandra Harding, por exemplo, podemos separá-las em duas principais abordagens, ${ }^{13}$ digamos, clássicas: por um lado, a do construtivismo social radical - poderiamos pensar como exemplo Foucault, ${ }^{14}$ Butler ${ }^{15}$ e Preciado ${ }^{16}$ - e, por outro, um "empiricismo feminista", que mantém uma suspeita à relativização da objetividade feita pelo construtivismo radical e detém-se em uma prática critica de reconhecimento de explicações sérias sobre a objetividade no mundo.

O construtivismo social radical parte do

\footnotetext{
9 GOLDMAN, Alvin. Why Social Epistemology Is Real Epistemology. In: HADDOCK, A.; MILLAR, A.; PRITCHARD, D. (ed.). Social Epistemology. New York, US: OUP, 2010. p. 1-28.

10 GOLDMAN, A. Why Social Epistemology Is Real Epistemology. In: HADDOCK, A.; MILLAR, A.; PRITCHARD, D. (ed.). Social Epistemology New York, US: OUP, 2010. p. 19.

11 HARAWAY, Donna. Saberes localizados: a questão da ciência para o feminismo e o privilégio da perspectiva parcial. Cadernos Pagu Campinas, n. 5. p. 7-41, 1995.

12 HARAWAY, Donna. Saberes localizados: a questão da ciência para o feminismo e o privilégio da perspectiva parcial. Cadernos Pagu Campinas, n. 5. p. 7-41, 1995. p. 29

13 HARDING, S. The Science Question in Feminism. Ithaca, US: Cornell University, 1986. p. 24

14 FOUCAULT, M. A verdade e as formas juridicas. Rio de Janeiro: Nau, 2005

15 BUTLER, J. Gender Trouble. New York: Routledge, 2015

16 PRECIADO, Paul. Texto Junkie: sexo, drogas e biopolitica na era farmacopornográfica. Trad. Maria Paula Gurgel Ribeiro. São Paulo: N-1 Edições, 2018.
} 
pressuposto de analisar de forma crítica os marcadores de objetividade utilizados no discurso científico e filosófico. Aqui, o agente epistêmico parte de uma perspectiva "generificada" que conta com a experiência de mundo subjetivada como parâmetro de racionalidade, justificação e verdade. Retomando a argumentação de Foucault em $A$ verdade e as formasjuridicas, o conhecimento éalgo inventado, que não tem origem e "como as práticas sociais podem chegar a engendrar domínios de saber que não somente fazem aparecer novos objetos, novos conceitos, novas técnicas, mas também fazem nascer formas totalmente novas de sujeitos e de sujeitos de conhecimento".17 Assim, para Foucault, a verdade tem uma história, isto é, a partir de um conhecimento possivel, a verdade aparece. Inspirada pela leitura foucaultina, Butler em Problemas de Gênero ${ }^{18}$ critica a universalização categorial do gênero (homem/mulher) pautado por argumentos biológicos que afirmam uma natureza originária imutável. Para Butler, o gênero ocorre apenas na esfera discursiva - as práticas sociais de articulação do poder que as tornam categorias "verdadeiras" que significam a realidade.

Esse tipo de argumento subjetivista é benéfico para leituras feministas na medida em que apresentam uma forma de questionar e de revisar o conhecimento científico e biológico do sexo e do gênero para além das afirmações machistas que visavam afirmar um lugar de submissão à mulher. Segundo Harding, essa proposta ajudava a colocar a ciência sob a perspectiva de uma "atividade totalmente social", que de várias formas expressam estruturas socialmente estabelecidas de gênero. ${ }^{19}$
Se nós abandonarmos todos esses dogmas do empirismo, poderiamos adotar a visão alternativa de que a ciência é uma atividade plenamente social - tão especificamente social e cultural quanto são as atividades religiosas, educacionais, econômicas e familiares. Encontrariamos, então, valor crítico nas perspectivas interpretativas de todas as atividades que contam como científicas, assim como todas aquelas que tornam a atividade cientíica possivel [...] e que tornam possivel que alguém seja cientista, selecionando, financiando, e desenvolvendo as tecnologias necessárias para seguir com a pesquisa científica e que tornam essas pesquisas possiveis, atribuam diferentes significados e valor social a razão científica e da razão moral, politica e emocional. ${ }^{20}$

Adotar esse método de crítica interpretativa da ideia de origem e de uma biologia fixa enquanto uma verdade absoluta permitiu-nos apontar que muitas vezes a análise e a metodologia foram consideradas neutras quando, na verdade, elas faziam parte desses conjuntos de significantes sociais que também se incorporavam na pesquisa cientifica. Tornou-se possivel questionar, por exemplo, o trabalho científico de Tranel et al., em Does gender play a role in functional asymmetry of ventromedial prefrontal cortex? ${ }^{21}$ e Sex-related functional asymmetry of the amygdala, ${ }^{22}$ no qual ele afirma que as diferenças morfológicas (como tamanho) e aspectos funcionais (sua função inter-hemisférica nas mulheres e da função intrahemisférica nos homens) são bases suficientes para descrever estratégias e tomada de decisão a partir das diferenças sexuais, inclusive em práticas sociais como a escolha de carreira, a economia familiar e as dinâmicas de relacionamento. ${ }^{23}$

Essa análise de Tranel et al. dava ênfase às diferenças entre homens e mulheres, servindo para uma argumentação pautada em dados

\footnotetext{
FOUCAULT, M. A verdade e as formas juridicas. Rio de Janeiro: Nau, 2005. p. 8.

BUTLER, J. Gender Trouble. New York: Routledge, 2015

HARDING, S. The Science Question in Feminism. Ithaca, US: Cornell University, 1986. p. 57.

HARDING, S. The Science Question in Feminism. Ithaca, US: Cornell University, 1986. p. 56-57. Do original: If we were to abandon these dogmas of empiricism, we could adopt the alternative view that science is a fully social activity-as social and as culturally specific as are religious, educational, economic, and family activities. We would then find valuable critical interpretive approaches to all the activities that count as scientific, as well as to those that make scientific activity possible [...] that make it possible for some people to be scientists: selecting, funding, and developing the technologies necessary to carry out scientific inquiry and those that inquiry makes possible; assigning different social meanings and values to scientific reason and to moral, political, and emotional reason.

${ }_{21}$ TRANEL, D.; DAMASIO, H.; DENBURG, N. L.; BECHARA, A. Does gender play a role in the functional asymmetry of ventromedial prefrontal cortex? Brain, v. 128, n. 12, p. 2872-2881, 2005. Disponivel em: https://doi.org/10.1093/brain/awh643. Acesso em: 29 jan. 2020

22 TRANEL, D.; BECHARA, A. Sex-related functional asymmetry of the amygdala: preliminary evidence using a case-matched lesion approach. Neurocase: The Neural Basis of Cognition, v. 15, n. 3. p. 217-234, 2009. Disponivel em: https://doi.org/10.1080/13554790902775492. Acesso em: 30 jan. 2020.

23 GUERIM, L. D.; PONTIN, F.; BARBOSA, C. P.; TERNUS; B. F. Sexual identity and neurosexism: a critique of reductivist approaches of sexual behavior and gender". Dossiê Naturalismo, Dissertatio, Pelotas, v. 5. suplemento, 2017. p. 24
} 
cientíicos das dinâmicas sexistas sociais como, por exemplo, a escolha de determinadas profissões por homens e outras por mulheres que, antes de uma análise social, era justificado por diferenças morfológicas no cérebro. Essa distinção entre homens e mulheres na neurociência, entretanto, não passou sem críticas; como se pode ver pela análise de Janet Hyde ${ }^{24}$ e Cordelia Fine ${ }^{25}$ que apontam para como - ao contrário do que a tradição neurocientífica parece sugerir - há mais pontos em comum e similares entre os gêneros, do que não. Nesse sentido, para ambas as autoras, devido à neuroplasticidade - isto é, a capacidade do cérebro de ser flexivel, de moldar sua morfologia de acordo com o impacto social - e a falta de um marcador definitivo em que a biologia humana pudesse existir completamente desvinculada do aspecto social, as conclusões das diferenças sociais poderiam ser lidas como resultantes da análise feita por homens dentro de um contexto sexista que utiliza marcadores supostamente neutros em suas análises. ${ }^{26}$

Para Haraway, essa perspectiva deixa "claro que as ideologias oficiais sobre a objetividade e o método científico são péssimos guias, particularmente no que diz respeito a como o conhecimento científico é realmente fabricado". ${ }^{27}$ Aqui, o construtivismo articula a ideia de conhecimento e verdade com o campo prático do poder, ou seja, a ciência seria um tipo de "jogo" da verdade, com interesses particulares em determinados discursos, que criam e se apropriam do método como caminhos de estruturação da convicção em fatos e artefatos que forjam a realidade.

A História é uma estória que os entusiastas da cultura ocidental contam uns aos outros; a ciência é um texto contestável e um campo de poder; o conteúdo é a forma. Ponto. A forma na ciência é retórica artefactual-social de fabricar o mundo através de objetos efetivos. Esta é uma prática de convicções que mudam o mundo e que tomam a forma de incriveis objetos novos - como os micróbios, os quarks e os genes. ${ }^{28}$

Contudo, tanto Haraway quanto Harding apontam para os limites dessa perspectiva na argumentação epistemológica feminista. Ao argumentar que a ciência, o método e a realidade são, de fato, criacionismos sociais, então toda perspectiva feminista não passa também de uma ficção, de uma narrativa a partir de uma perspectiva própria. Nesse sentido, dizer que homens e mulheres são inerentemente diferentes, ou dizer que são inerentemente iguais, são ficções criadas dentro da linguagem e do discurso e que se concretizam pelas práticas sociais, mas não há nenhum apelo maior de verdade em qualquer um deles.

Para Haraway, com essa metodologia "terminamos com uma espécie de terapia de eletrochoque epistemológica que, longe de conduzir-nos às questões importantes do jogo de contestação das verdades públicas, derrubounos vítimas do mal da personalidade múltipla auto-induzida". ${ }^{29}$ Desse modo, ficamos presas a essa narrativa relativista da realidade, que tanto nos afasta como pertencentes ao jogo científico, quanto nos coloca necessariamente em uma visão corporificada da verdade, apenas em um nivel subjetivista. Ainda, segundo Harding, a contribuição da perspectiva feminista nessas disputas acerca da realidade deveria "fazer contribuições significativas em esclarecer a natureza e implicações de tendências paradoxais na vida intelectual e social contemporânea".30 Assim, ambas autoras buscam um viés alternativo para essa dicotomia acerca do conhecimento, mostrando que a perspectiva feminista é uma espécie de ramificação ou está mesmo incorporada à ciência e à epistemologia.

\footnotetext{
HYDE, J. The Gender Similarities Hypothesis. Am. Psych., v. 6o, n. 6, 2005. p. 581-592.

FINE, C. Is There Neurosexism in Functional Neuroimaging Investigations of Sex Difference? Neuroethics, v.6, n. 2, p. 369-409, ago. 2013. GUERIM, Laura; PONTIN, Fabricio; BARBOSA, Camila; TERNUS; Bruna. Sexual identity and neurosexism: a critique of reductivist approaches of sexual behavior and gender. Dossiê Naturalismo, Dissertatio, Pelotas, v. 5, suplemento, 2017, p. 24.

27 HARAWAY, Donna. Saberes localizados: a questão da ciência para o feminismo e o privilégio da perspectiva parcial. Cadernos Pagu. Campinas, n. 5. p. 7-41, 1995. p. 9.

28 HARAWAY, Donna. Saberes localizados: a questão da ciência para o feminismo e o privilégio da perspectiva parcial. Cadernos Pagu, Campinas, n. 5, p. 7-41, 1995. p. 10-11.

29 HARAWAY, Donna. Saberes localizados: a questão da ciência para o feminismo e o privilégio da perspectiva parcial. Cadernos Pagu, Campinas, n. 5, p. 7-41, 1995. p. 13

30 HARDING, S. The Science Question in Feminism. Ithaca, US: Cornell University, 1986. p. 28
} 
Por outro lado, temos diversos argumentos que partem do pressuposto de uma experiência única da mulher, tanto no que se refere à natureza (biologia) quanto na vivência social. O "empiricismo feminista" parte de evidências ou fatos científicos que reafirmam um ponto de vista particular feminista na ciência, isto é, uma pesquisa a partir da perspectiva feminista encontraria fatos diferentes sobre a natureza e objetividade do mundo do que aquela feita por homens. No texto "Hand, Brain, and Heart: A Feminist Epistemology for the Natural Sciences", Hilary Rose afirma que a ciência precisa de um novo ponto de vista, que incorpore a possibilidade de construir visões alternativas das ciências e tecnologias, que carreguem investigações sob certas condições e períodos históricos. ${ }^{31} \mathrm{Com}$ isso, Rose pretende desarticular a epistemologia não apenas de um domínio de classe, mas também de um domínio patriarcal reprimido, a partir da própria ciência, e não de uma crítica completa à sua metodologia.

Nesse sentido, teriamos a formação de uma "ciência natural feminista", que seria crítica à ciência tradicional masculina, que teria como ponto de desenvolvimento metodológico uma interpretação constantemente em contraste com a experiência de opressão da mulher. Aqui, já se nota que também é possivel articular o mesmo estilo de crítica ao argumento de Tranel et al. - a visão de Tranel et al. não leva em consideração a perspectiva da mulher e a sua relação de subordinação na estrutura social, o que impactaria tanto no sentido de formação morfológica quanto na tomada de decisão. Rose propõe uma análise que busca compreender os efeitos da divisão de atividades pautadas por gênero no conhecimento intelectual; o que questiona, também, a ideia de uma perspectiva de conhecimento neutra universal.

Para Rose, ainda, a crítica à ciência vinda de movimentos sociais na década de 1960 e 1970 (que atacaram a retórica imperialista, sexista e racista com a qual as principais linhas de análise se desenvolviam) estabelecia um diálogo quase impossivel entre ciência e ideologia. Nesse sentido, afirma:

\begin{abstract}
A necessidade de responder imediatamente aos ataques ideológicos de uma ciência racista ou sexista acelerou à medida que a crise se aprofundava; Era dificil, simultaneamente, resistir ao ataque e analisar os problemas. De fato, a hostilidade à ciência dentro do movimento combinou ciência e ideologia que ajudou no crescimento de atitudes que rejeitavam totalmente a ciência. ${ }^{32}$
\end{abstract}

Assim, o próprio movimento feminista, ao se apropriar de questões tanto subjetivas quanto objetivas, como por exemplo, o aborto, o autocuidado, a saúde pública da mulher etc., desenvolveu um novo tipo de conhecimento, que é tão pautado por métodos e análises empíricas quanto qualquer outra, mas que parte desse lugar específico de fala e de experiência, trazendo um novo saber. ${ }^{33}$ Uma vantagem da epistemologia feminista a partir desse ponto de vista é que coloca em xeque a falta de representação naqueles espaços que normalmente são predominantemente masculinos, brancos e heterossexuais - a perspectiva a partir do próprio eu, ainda que utilize dos mesmos métodos, contribui para demandar maior igualdade de representação nesses ambientes. Por isso, Rose vê essa ciência feminista como um tipo de organismo vivo, atuante, que possibilita o conhecimento da biologia em que está implicado. ${ }^{34}$

Harding aponta que a ideia desse organismo vivo proposta por Rose, na verdade, cai na mesma determinação da natureza de argumentos que são permitidos apenas para um grupo, fato que feministas tem questionado na ciência há muito tempo. ${ }^{35}$ Se a ciência feita a partir do ponto de vista e da experiência social de gênero é válida

\footnotetext{
${ }^{31}$ ROSE, Hilary. Hand, Brain, and Heart: A Feminist Epistemology for the Natural Sciences. Signs: Journal of Women in Culture and Society Chicago, v. 9. n. 1, p. 73-90, 1983. p. 76.

32 ROSE, Hilary. Hand, Brain, and Heart: A Feminist Epistemology for the Natural Sciences. Signs: Journal of Women in Culture and Society, Chicago, v. 9. n. 1, p. 73-90, 1983. p. 76

33 ROSE, Hilary. Hand, Brain, and Heart: A Feminist Epistemology for the Natural Sciences. Signs: Journal of Women in Culture and Society, Chicago, v. 9. n. 1, p. 73-90, 1983. p. 82.

34 ROSE, Hilary. Hand, Brain, and Heart: A Feminist Epistemology for the Natural Sciences. Signs: Journal of Women in Culture and Society. Chicago, v. 9, n. 1, p. 73-90, 1983. p. 88.

35 HARDING, S. The Science Question in Feminism. Ithaca: Cornell University, 1986. p.144-145.
} 
como uma alternativa de conhecimento, então, não há nada de errado com a versão não neutra masculina na qual toda história da ciência se desenvolveu - faz parte do mesmo método e gera um conhecimento específico. Para Haraway, essa limitação ocorre por nossa insatisfação em aplicar esse jogo de poder como prática científica, como articulação da objetividade.

[...] os debates a respeito da objetividade são relevantes, seja metaforicamente ou não. Imortalidade e onipotência não são nossos objetivos. Mas poderíamos fazer uso de algumas explicações confiáveis, aplicáveis, sobre as coisas, que não fossem redutiveis a lances de poder e a jogos de retórica de alto coturno, agonísticos, ou à arrogância cientificista, positivista. Esta proposta se aplica quer estejamos falando a respeito de genes, classes sociais, partículas elementares, gêneros, raças ou textos; aplica-se às ciências exatas, naturais, sociais e humanas, apesar das ambiguidades escorregadias das palavras objetividade e ciência conforme circulamos pelo terreno discursivo. ${ }^{36}$

É preciso mais que uma ficção narrativa sobre o poder e a subjetividade, pois não se poderia diferenciar ou qualificar um argumento bem estruturado, por exemplo, a favor da descriminalização do aborto daquele do discurso inflamado de alguns sistemas religiosos que lutam contra a possibilidade de escolha da continuação da gestação, uma vez que nenhum dos dois discursos apresentariam mais verdade ou mais conhecimento. Também não é suficiente pensar em um empirismo de um único ponto de partida, que justificasse amplamente versões alternativas da realidade. Mas Haraway percebe bem como a epistemologia feminista acaba ficando presa a essa dicotomia como se fosse uma antitese, quando, na verdade, poderiamos estar percorrendo um caminho inclusivo, uma vez que "precisamos do poder das teorias críticas modernas sobre como significados e corpos são construidos, não para negar significados e corpos, mas para viver em significados e corpos que tenham a possibilidade de um futuro". ${ }^{37} \mathrm{~A}$ proposta de "saberes localizados", de Haraway, e a de "ciência da sucessão", de Harding, surgem como uma tentativa de promover essa junção, fornecendo uma epistemologia feminista para além dessa dicotomia.

\section{Epistemologia feminista a partir dos saberes localizados e a ciência da sucessão}

Qual seria esse caminho não dicotômico entre "empirismo feminista" e construtivismo social radical? Em grande medida, Haraway busca em seus textos articular os impactos da relação semiótica entre biologia e tecnologias, criando um tipo de subjetividade que se atenta às objetividades da realidade na qual determinados corpos são alocados de maneira diferente. Ao mesmo tempo, ela olha para o mundo tecnológico como um universo de possibilidades de acessar essa objetividade e construir, a partir do ponto de vista, uma ficção que transcenda a monótona narrativa fixa e regulada de nossa existência. Haraway pretende apresentar um novo olhar, partindo justamente da perspectiva da visão: esse "sistema sensorial que tem sido utilizado para significar um salto para fora do corpo marcado, para um olhar conquistador que não vem de lugar nenhum".38

O olho é um órgão não binário, nem masculino, nem feminino; nem somente humano, nem somente animal; nem somente biológico, nem somente tecnológico. ${ }^{39}$ A tecnologia ampliou o alcance da visão, e seu poder de inscrever significados no mundo, daqueles que têm ou que não têm o poder narrativo do conhecimento (que possui uma capacidade de "truque": "todas as perspectivas cedem passagem a uma visão infinitamente móvel, que parece ser não mais apenas a respeito do truque mítico de deus de ver tudo de lugar nenhum, mas da transformação

\footnotetext{
36 HARAWAY, Donna. Saberes localizados: a questão da ciência para o feminismo e o privilégio da perspectiva parcial. Cadernos Pagu Campinas, n. 5, p. 7-41, 1995. p. 17.

37 HARAWAY, Donna. Saberes localizados: a questão da ciência para o feminismo e o privilégio da perspectiva parcial. Cadernos Pagu. Campinas, n. 5. p. 7-41, Campinas, SP: 1995. p. 16.

38 HARAWAY, Donna. Saberes localizados: a questão da ciência para o feminismo e o privilégio da perspectiva parcial. Cadernos Pagu, Campinas, n. 5. p. 7-41, 1995. p. 18

39 HARAWAY, Donna. Saberes localizados: a questão da ciência para o feminismo e o privilégio da perspectiva parcial. Cadernos Pagu. Campinas, n. 5, p. 7-41, 1995. p. 22
} 
do mito em prática comum".40

Quero uma escrita feminista do corpo que enfatize metaforicamente a visão outra vez, porque precisamos resgatar esse sentido para encontrar nosso caminho através de todos os truques e poderes visualizadores das ciências e tecnologias modernas que transformaram os debates sobre a objetividade. Precisamos aprender em nossos corpos, dotados das cores e da visão estereoscópica dos primatas, como vincular o objetivo aos nossos instrumentos teóricos e políticos de modo a nomear onde estamos e onde não estamos, nas dimensões do espaço mental e físico que mal sabemos como nomear. ${ }^{41}$

Assim, Haraway pensa a objetividade enquanto uma visão que se releva a partir da incorporação particularista e especifica do conhecimento, e que não promete uma visão de verdade transcendental e que exima a responsabilidade analítica. A visão objetiva é sempre parcial, ela revela tanto a localização limitada, quanto o conhecimento localizado de ambos na relação sujeitos e objetos.

Da mesma forma, Harding também parece apreciar uma epistemologia feminista que saia desse confronto, dessa dicotomia, uma vez que nos faz enfrentar os dilemas e tensões que afastam o feminismo da ciência e a ciência do social. Pelo contrário, essa proposta de epistemologia feminista que abrace plenamente essa tensão, na verdade, cria uma análise crítica feminista, que é aberta à possibilidade de reconhecimento e apreciação de projetos aparentemente impossiveis de correlacionar. A epistemologia feminista é, portanto, inerentemente uma prática critica; pois vê, a partir desses polos de argumentação, a evolução das relações entre sujeitos e os objetos do mundo, e como elas estão em constante modificação. Por isso, uma teoria feminista que alegasse uma versão final sobre o conhecimento e a verdade estaria "historicamente prematura e iludida". Harding afirma que:
As relações sociais que são nosso objetivo de estudo, que nos criam e recriam como agentes de conhecimento e dentro do qual nossas categorias analíticas são formadas e testadas, são elas mesmas em exuberante transformação. Razão, força de vontade, "trabalhando mais o material ", mesmo a luta política não vai resolvê-los agora de maneiras pelas quais o feminismo deve se alegrar. ${ }^{42}$

A ciência da sucessão sugere que a análise da objetividade seja também relacionada com uma crítica reflexiva de práticas sociais de dominação e privilégios, que contemplem explicações mais adequadas do mundo a partir dessa "união com a ciência". Se por um lado a ciência apresenta teorias totalizantes, que afirmam poder explicar de forma lógica todos os fenômenos da realidade, ela deixa no seu inconsciente todo um universo de significantes como emoções, sentimentos, valores politicos e morais, historicidade, etc. $\mathrm{O}$ projeto da epistemologia feminista é o de revelar esses dois mundos como parte de um mesmo, no qual "cada um molda e forma o outro".43

A ideia de saberes localizados difere-se da ciência de sucessão, pois consegue inserir um nivel de responsabilidade que, segundo Haraway, é essencial. Responsável, aqui, seria uma teoria que fosse possivel ser "chamada para prestar contas", eliminando a crítica do empirismo feminista de uma ausência de responsabilização do processo de conhecimento. Haraway quer desafiar a própria posição estável no jogo de poder do conhecimento daqueles subjugados, estes também precisam e devem passar por uma revisão crítica de interpretação, codificação e avaliação. Nesse sentido, "a alternativa ao relativismo são saberes parciais, localizáveis, críticos, apoiados na possibilidade de redes de conexão, chamadas de solidariedade em política e de conversas compartilhadas em epistemologia".44

Localizar os saberes é, também, situar a epistemologia no tempo, como afirma Miranda

\footnotetext{
40 HARAWAY, Donna. Saberes localizados: a questão da ciência para o feminismo e o privilégio da perspectiva parcial. Cadernos Pagu Campinas, n. 5, p. 7-41, 1995. p. 19.

41 HARAWAY, Donna. Saberes localizados: a questão da ciência para o feminismo e o privilégio da perspectiva parcial. Cadernos Pagu. Campinas, n. 5. p. 7-41, 1995. p. 20-21.

42 HARDING, S. The Science Question in Feminism. Ithaca, US: Cornell University, 1986. p. 244.

43 HARDING, S. The Science Question in Feminism. Ithaca, US: Cornell University, 1986. p. 245.

44 HARAWAY, DONNA. Saberes localizados: a questão da ciência para o feminismo e o privilégio da perspectiva parcial. Cadernos Pagu, Campinas, n. 5, p. 7-41, 1995. p. 23
} 
Fricker, ${ }^{45}$ no qual os sujeitos epistêmicos ficam entre as relações de conhecedores finitos e inquiridores que carregam razões, produzem evidências, buscam informações etc. ${ }^{46}$ Nesse sentido, Fricker sugere que a epistemologia incorpore "Concepções Sociais Situadas", nas quais categorias sociais de identidade e de relações de poder integrariam as questões epistemológicas.

Se queremos que a epistemologia explique a situação epistêmica humana, então precisamos ter disponivel uma concepção de sujeitos epistêmicos, conforme necessário, para superar ou negociar certos enredos da razão e do poder, porque é uma característica essencial do ser humano inquiridor que ele opere em um contexto em que tais complicações podem surgir. Isto é a fonte do valor da Concepção Social Situada, que concebe temas epistêmicos e suas interações situadas em um contexto de identidade social e poder, e então torna visivel a influência desses fatores nas nossas interações epistêmicas (tradução nossa). ${ }^{47}$

Retomando Haraway, essas concepções situadas da epistemologia servem em favor de uma doutrina e prática da objetividade, mas que possam ser contestados, descontruidos e transformados em novas formas de conhecimento. Assim, é preciso que a epistemologia feminista também busque aquelas perspectivas mais marginalizadas, que retire o conhecimento das mãos exclusivas dos eixos de dominação. Trata-se de um perspectiva que seja a junção do imaginário e do racional, isto é, da visão visionária e revolucionária da objetividade.

O Eu dividido e contraditório é o que pode interrogar os posicionamentos e ser responsabilizado, o que pode construir e juntar-se às conversas racionais e imaginações fantásticas que mudam a história. Divisão, e não o ser, é a imagem privilegiada das epistemologias feministas do conhecimento científico. «Divisão», neste contexto, deve ser vista como multiplicidades heterogêneas, simultaneamente necessárias e não passiveis de serem espremidas em fendas isomórficas ou listas cumulativas. ${ }^{48}$

A proposta da epistemologia feminista, portanto, de Haraway, Harding, e até Fricker, é a de pensar em um Eu cognoscente parcial, que nunca está completo, mas que é um conhecedor científico, que "procura a posição de identidade com o objeto, mas de objetividade, isto é, de conexão parcial".49 Assim, a objetividade serve como instrumentos de visão, que mediam pontos de vista, que se posiciona e se responsabiliza, e que oferece posições de objetividade corporificada.

\section{Considerações finais}

A epistemologia feminista aparece como uma ramificação da epistemologia social na medida em que considera como agentes epistêmicos a coletividade e as inclui nas formas de conhecimento e raciocinio enquanto efeito dessas relações dinâmicas sociais. Uma abordagem feminista, de uma forma ou de outra, vai estar interessada no efeito do fenômeno social do gênero e suas implicações na sociedade e na história do saber, uma vez que questiona e aponta para leituras que utilizam a ciência como metodologia de reafirmação do status social, e que não são suficientemente reflexivos quanto a essa relação pouco separável entre natureza e sociedade.

A tentativa de trazer uma análise epistêmica como a de Haraway e Harding parece permitir aproximar a questão do feminismo da questão da ciência, e adentrar nesse campo que determina o que é conhecimento a partir de um ponto de partida já crítico aos modelos da epistemologia

\footnotetext{
45 FRICKER, M. Scepticism and the Genealogy of Knowledge: Situating Epistemology in Time. HADDOCK, A.; MILLAR, A.; PRITCHARD, D. (ed.). Social Epistemology. New York, US: OUP, 2010. p. 51-68.

46 FRICKER, M. Scepticism and the Genealogy of Knowledge: Situating Epistemology in Time. In: HADDOCK, A.; MILLAR, A.; PRITCHARD, D. (ed.). Social Epistemology. New York, US: OUP, 2010. p. 51.

47 FRICKER, M. Scepticism and the Genealogy of Knowledge: Situating Epistemology in Time. In: HADDOCK, A.; MILLAR, A.; PRITCHARD, D. (ed). Social Epistemology. New York, US: OUP, 2010. p. 53. Do original: If we want epistemology to account for the human epistemic predicament, then we need to have available a conception of epistemic subjects as required to overcome or negotiate certain entanglements of reason and power, because it is an essential feature of human enquirers that they operate in a context in which such entanglements can arise. This is the source of the value of the Situated Social Conception, which conceives epistemic subjects and their interactions as situated in a context of social identity and power, and so makes visible the influence of these factors on our epistemic interactions"

48 HARAWAY, DONNA. Saberes localizados: a questão da ciência para o feminismo e o privilégio da perspectiva parcial. Cadernos Pagu Campinas, n. 5. p. 7-41, 1995. p. 26

49 HARAWAY, Donna. Saberes localizados: a questão da ciência para o feminismo e o privilégio da perspectiva parcial. Cadernos Pagu. Campinas, n. 5, p.7-41, 1995. p. 26.
} 
analítica tradicional que ignora que seus pesquisadores fazem tão parte desse mundo ao qual eles olham, quanto seus sujeitos de pesquisa.

Ainda, tentei ao mesmo tempo separar essa visão da epistemologia feminista daquelas categorias apresentadas por Goldman. Primeiro, pois não podem ser categorizados nem como exclusivamente internalista, nem exclusivamente externalista, como afirma Harding "os estudos internalistas e externalistas da ciência, então, são irremediavelmente falhos".50 Pegando a premissa de Haraway da visão como exemplo, vemos tanto uma noção biológica e natural, quanto um adendo tecnológico que excede os limites da descrição tradicional do que a visão realmente é, para início de conversa. Segundo, ela não busca revisar o material epistemológico tradicional, não oferece apenas uma expansão do que entendemos como conhecimento incluindo aspectos sociais como parte do processo, tampouco vê formas de preservar boa parte do campo tradicional da epistemologia e acrescentar evidencias sociais. A epistemologia feminista é outra perspectiva de análise, ela é a implosão dos dualismos, incorporação das suas contradições e tensões, e articulação de uma explicação reflexiva e crítica dos elementos de análise epistêmica.

\section{Referências}

BUTLER, J. Gender Trouble. New York: Routledge, 2015.

FINE, C. Is There Neurosexism in Functional Neuroimaging Investigations of Sex Difference? Neuroethics, [s. l.], v. 6, n. 2, p. 369-409, ago. 2013. Disponivel em: https://doi.org/10.1007/s12152-012-9169-1. Acesso em: 30 jan. 2020.

FINE, C. Gender Similarities and Differences. Annual Review of Psychology, v. 65, p. 373-398, jan. 2014. Disponivel em: https://doi.org/10.1146/annurev-psych-010213-115057. Acesso em: 30 jan. 2020.

FOUCAULT, M. A verdade e as formas juridicas. Rio de Janeiro: Nau, 2005.

FRASER, N. Rethinking the Public Sphere: contribution to the critique of actually existing democracy. Social Text, Durham, n. 25/26, p. 56-80, 1990. https://doi. org/10.2307/466240.
FRICKER, M. Scepticism and the Genealogy of Knowledge: Situating Epistemology in Time. In: HADDOCK, A.; MILLAR, A.; PRITCHARD, D. (ed.). Social Epistemology. New York: OUP, 2010. p. 51-68. https://doi.org/10.1093/ acprof:0so/9780199577477.003.0003.

GOLDMAN, A. Why Social Epistemology Is Real Epistemology. In: HADDOCK, A.; MILLAR, A.; PRITCHARD, D. (ed.). Social Epistemology. New York: OUP, 2010. p. 1-28. https://doi.org/10.1093/acprof:0so/9780199577477.003.0001.

GUERIM, L. D.; PONTIN, F.; BARBOSA, C. P.; TERNUS; B. F. Sexual identity and neurosexism: a critique of reductivist approaches of sexual behavior and gender. Dossiê Naturalismo, Dissertatio, Pelotas, v. 5, supl., 2017. Disponivel em: https://periodicos.ufpel.edu.br/ojs2/index.php/ dissertatio/article/view/11077. Acesso em: 30 jan. 2020

HADDOCK, A.; MILLAR, A.; PRITCHARD, D. (ed.). Social Epistemology. New York, US: OUP, 2010. https://doi. org/10.1093/acprof:0so/9780199577477.001.0001.

HARAWAY, D. Saberes localizados: a questão da ciência para o feminismo e o privilégio da perspectiva parcial. Cadernos Pagu, Campinas, n. 5, p. 7-41, 1995. Disponivel em: http://bit.ly/2RWVOCc. Acesso em: 03 set. 2019.

HARDING, S. The Science Question in Feminism. Ithaca, US: Cornell University, 1986.

HYDE, J. The Gender Similarities Hypothesis. American Psychologist, Washington, v. 60, n. 6, p. 581-592, set. 2005. Disponivel em: https://doi.org/10.1037/ 0003-066X.60.6.581. Acesso em: 30 jan. 2020.

JAGGAR, A. M. Love and knowledge: Emotion in feminist epistemology. Inquiry: An Interdisciplinary Journal of Philosophy, London, v. 32, n. 2, p.151-176, 1989. Disponivel em: https://doi.org/10.1080/00201748908602185. Acesso em: 30 jan. 2020.

PRECIADO, P. Texto Junkie: sexo, drogas e biopolitica na era farmacopornográfica. Trad. Maria Paula Gurgel Ribeiro. São Paulo: N-1 Edições, 2018.

ROSE, H. Hand, Brain, and Heart: A Feminist Epistemology for the Natural Sciences. Signs: Journal of Women in Culture and Society, Chicago, v. 9, n. 1, p. 73-90, 1983. Disponivel em: http://www.jstor.org/stable/3173664. Acesso em: 30 jan. 2020.

TRANEL, D.; BECHARA, A. Sex-related functional asymmetry of the amygdala: preliminary evidence using a case-matched lesion approach. Neurocase: The Neural Basis of Cognition, [s. l.], v. 15, n. 3, p. 217-234, 2009. Disponivel em: https://doi.org/10.1080/13554790902775492. Acesso em: 30 jan. 2020.

TRANEL, D.; DAMASIO, H.; DENBURG, N. L.; BECHARA, $A$. Does gender play a role in the functional asymmetry of ventromedial prefrontal cortex? Brain, [s. l.], v. 128, n. 12, p. 2872-2881, 2005. Disponivel em: https://doi. org/10.1093/brain/awh643. Acesso em: 29 jan. 2020. 


\section{Camila Palhares Barbosa}

Doutoranda no Programa de Pós-Graduação em Filosofia da Pontificia Universidade Católica do Rio Grande do Sul (PUCRS, Porto Alegre, RS, Brasil), bolsista da Coordenação de Aperfeiçoamento de Pessoal de Nivel Superior (Capes)

\section{Endereço para correspondência}

Camila Palhares Barbosa

Pontificia Universidade Católica do Rio Grande do Sul

Av. Ipiranga, 6.681, Prédio 4, sala 2

Partenon, 97010-082

Porto Alegre, RS, Brasil 